\title{
Regulatory role of microRNA-320 during off-pump coronary artery bypass grafting with dexmedetomidine adjunct anesthesia
}

\author{
YAN GAO ${ }^{1}$, XIAOLONG ZHU ${ }^{2}$, HUIDAN YU ${ }^{3}$, WENLONG WANG ${ }^{4}$, \\ YEMING WANG $^{1}$, FULONG LI ${ }^{1}$ and JINLIANG TENG ${ }^{1}$ \\ Departments of ${ }^{1}$ Anesthesiology, ${ }^{2}$ Medical Imaging and ${ }^{3}$ Ultrasound; ${ }^{4}$ Operating Room, \\ The First Affiliated Hospital of Hebei North University, Zhangjiakou, Hebei 075000, P.R. China
}

Received February 14, 2020; Accepted June 1, 2021

DOI: $10.3892 / \mathrm{etm} .2021 .10635$

\begin{abstract}
The present study investigated the effects of dexmedetomidine on the expression level of microRNA-320 (miR-320) and neuroglobin (NGB) in patients undergoing off-pump coronary artery bypass grafting (OPCABG). A total of 40 patients undergoing OPCABG were recruited and randomly divided into the dexmedetomidine and normal saline groups (treated before anesthesia), respectively. The NGB levels in the blood samples before and after surgery were analyzed and compared. The CATH.a cells were cultured and induced with dexmedetomidine, and the NGB expression level was detected. CATH.a cells were treated with NGB and lipopolysaccharide (LPS), and the cell survival rate was determined. The miR-320 expression levels in the blood samples and dexmedetomidine-induced cells were detected. Dual-luciferase reporter assay was performed. Compared with control subjects, patients in the dexmedetomidine group had higher NGB levels in the blood. In the CATH.a cells, the dexmedetomidine treatment upregulated the NGB levels. Moreover, upon pre-incubation with NGB and LPS stimulation, dexmedetomidine elevated cell viability. Furthermore, miR-320 expression levels were significantly downregulated in the blood of patients in the dexmedetomidine group, as well as in the dexmedetomidine-induced cells. Dual-luciferase reporter assay confirmed that miRNA-320a directly targeted on NGB, and upregulated miRNA-320a in CATH.a cells decreased cell proliferation activity. Pre-administration of dexmedetomidine can decrease miR-320 expression level in the blood of patients undergoing OPCABG, stimulating the high expression of NGB and increasing the proliferation activity
\end{abstract}

Correspondence to: Dr Jinliang Teng, Department of Anesthesiology, The First Affiliated Hospital of Hebei North University, 12 Changqing Street, Zhangjiakou, Hebei 075000, P.R. China

E-mail: tengjinliang@126.com

Key words: microRNA-320, off-pump coronary artery bypass grafting, dexmedetomidine adjunct anesthesia of neuronal cells, which may decrease the postoperative cognitive impairment.

\section{Introduction}

Post-operative cognitive dysfunction (POCD) has been characterized by the progressive memory loss, personality changes and/or post-operation cognitive function deterioration $(1,2)$. The incidence rate of POCD in patients receiving general anesthesia is increased (3). The off-pump coronary artery bypass grafting (OPCABG) completely avoids the systemic inflammatory response caused by extracorporeal circulation and reduces the blood transfusion rate, which, however, is still arguable (4-6). The intraoperative operation represents the key factor leading to the instability of the hemodynamics. In some severe cases, the sudden and violent fluctuations of the hemodynamics might lead to POCD, together with the effects from anesthesia (7).

Neural damages might be one of the pathological manifestations of POCD. Dexmedetomidine is a newly discovered adrenergic receptor agonist, with high specificity to the adrenergic $\alpha_{2}$ receptor. Dexmedetomidine is an auxiliary anesthetic drug, which does not interfere with hemodynamics, characterized by low respiratory inhibition effect and ease of waking up after application. Dexmedetomidine would prevent the propofol-induced hippocampal, thalamic and cortical damages (8), significantly decreasing the IL-6 and TNF- $\alpha$ levels, and increasing superoxide dismutase (SOD) activity during general anesthesia (9). In addition, it has long-term effects on the neurocognitive function, which could decrease the inflammation and protect the neurological function, after traumatic brain injuries (10), accompanied by the high efficiency of pharmacokinetics, as well as the anti-anxiety, anticonvulsant and anti-epilepsy effects (11).

The protective effects of neuroglobin (NGB) on brain cells has already been confirmed. Under ischemia and hypoxia stress, the survival ability of nerve cells would be significantly increased by NGB overexpression, and the expression of associated signal molecules involved in apoptosis response would also be downregulated $(12,13)$. In addition, NGB would eliminate hypoxia-induced organelle aggregation (14), and improve the induction of actin aggregation in mitochondrial transport (15). NGB is mainly distributed in the anterior 
lobes and subthalamic nuclei in human beings and murine models (16), which is specifically expressed in neurons, while less expressed in glial cells (17).

Several studies have shown that multiple miRNAs play important roles in the development of the nervous system, as well as the functional and pathological processes, which has been shown to be abnormally expressed during anesthesia (18-20), including the miR-320a family (21). Moreover, the miR-320a family has been predicted to be the upstream regulatory genes of NGB. The miR-320a has been shown to be able to increase the neurite length, while decreasing the total cell number, which has been considered as a potential target for promoting the neuronal regeneration following injuries (22). However, the regulatory effect of miR-320a on NGB, and whether the gene expression levels in the human body would be affected by dexmedetomidine, have not been fully elucidated thus far.

Based on the aforementioned findings, the present study was based on the hypothesis that the dexmedetomidine adjunct anesthesia might protect the cognition function of patients receiving OPCABG, involving the regulatory network of miR-320a and NGB. Therefore, the present study investigated the role of miR-320a/NGB in dexmedetomidine adjunct anesthesia, and the expression levels of NGB and miR-320s in the blood samples of the patients undergoing OPCABG with dexmedetomidine adjunct anesthesia were detected and studied. Moreover, the association between the NGB and miR320 was predicted and analyzed.

\section{Materials and methods}

Study subjects. In total, 40 patients, 12 males and 8 females, aged 33-60 years (with a median age of 40.8 years), who underwent the OPCABG in the First Affiliated Hospital of Hebei North University, between August 2014 and August 2018 and 20 normal subjects, 13 males and 7 females, aged 31-61 years (with a median age of 41.9 years), serving as a control, were included in the present study. These patients were randomly divided into the following two groups $(n=20)$, based on a random number table: i) Dexmedetomidine group, in which the patients were given dexmedetomidine before anesthesia; and ii) control group, in which the patients were given saline before anesthesia. The exclusion criteria were as follows: Those with i) history of dementia and mental illness; ii) severe cerebrovascular diseases; iii) multiple surgical history; iv) history of severe infection in various systems during the perioperative period; v) large blood loss and severe acid-base balance and electrolyte imbalance in the perioperative period; vi) diabetes; and vii) severely abnormal liver and/or kidney function. Prior written and informed consent were obtained from every patient and the study was approved by the ethics review board of the First Affiliated Hospital of Hebei North University.

Anesthesia procedure. For both the dexmedetomidine and control groups, the patients were routinely fasted before surgery. Particularly, the off-pump surgery was performed, with $400 \mathrm{U} / \mathrm{kg}$ heparin and the ratio of heparin to protamine of $1: 1$. The patients were subjected to the venous access opening, oxygen mask, arterial blood pressure monitoring,
ECG, oxygen saturation monitoring and end-tidal carbon dioxide monitoring. Patients from the dexmedetomidine group underwent intravenous injection (by nurses, in a double-blinded manner) of $0.6 \mu \mathrm{g} / \mathrm{kg}$ dexmedetomidine within $15 \mathrm{~min}$ prior to anesthesia induction, and then pumped $\left(0.5 \mu \mathrm{g} \cdot \mathrm{kg}^{-1} \cdot \mathrm{h}^{-1}\right)$ until the end of surgery. On the other hand, the patients from the control group were given with an equal volume of $0.9 \%$ saline. For the intravenous induction, $2 \mathrm{mg}$ midazolam, $5 \mu \mathrm{g} / \mathrm{kg}$ sufentanil, $0.3 \mathrm{mg} / \mathrm{kg}$ etomidate and $0.3 \mathrm{mg} / \mathrm{kg}$ cis-atracurium were given. Following the induction of anesthesia, a small amount of propofol was continued via the intravenous infusion, and anesthesia was maintained with the intermittent intravenous injection of sufentanil and cis-atracurium. For the anesthesia management, when the blood pressure fluctuated by $>20 \%$ of the baseline value, norepinephrine and nitroglycerin would be supplemented. During surgery, intraoperative arterial blood gas analysis was performed, and the electrolyte, blood glucose, hematocrit, hemoglobin and lactic acid levels were monitored. When the values were beyond the normal range, timely intervention would be conducted to maintain the hemodynamic stability, internal environment and electrolyte balance. When the hemoglobin was $<80 \mathrm{~g} / 1$, the infused red blood cells should be administered. After the operation, the venous analgesia pump was connected, and the patient was sent into the ICU.

Specimen collection. One the days before and after surgery, respectively, $5 \mathrm{ml}$ blood sample was taken from the elbow vein before the blood test. The blood sample was placed in a test tube for $1 \mathrm{~h}$. The upper serum in the tube was collected and placed in another centrifuge tube. After centrifugation at $400 \mathrm{x} \mathrm{g}$ at $4^{\circ} \mathrm{C}$ for $10 \mathrm{~min}, 1.5 \mathrm{ml}$ serum sample was placed in an $\mathrm{EP}$ tube, and stored at $-80^{\circ} \mathrm{C}$ until further analysis.

Reverse transcription-quantitative $(R T-q) P C R$. Total RNA was extracted by TRIzol ${ }^{\circledR}$ (Thermo Fisher Scientific, Inc.). The cDNA template was obtained by reverse transcription with the miRcute miRNA cDNA first-strand synthesis kit (Tiangen Biotech Co., Ltd.) and the TIANScriptII cDNA first-strand synthesis kit (KR107; Tiangen Biotech Co., Ltd.), according to the manufacturer's instructions. Quantitative PCR was performed with the miRcute miRNA kit (cat. no. FP401; Tiangen Biotech Co., Ltd.) on the PCR-iQ5 qRT-PCR machine (Bio-Rad Laboratories, Inc.). The primer sequences was as follows: miR-320a upstream, 5'-GCGCAAAAGCTGGGT TGAGA-3'; miR-320a downstream, 5'-CAGTGCAGGGTC CGAGGT-3'; U6 upstream, 5'-CTCGCTTCGGCAGCACAT ATACT-3'; U6 downstream, 5'-ACGCTTCACGAATTT GCGTGTC-3'; NGB upstream, 5'-AAGGTGATGCTCGTG ATTGATG-3'; NGB downstream, 5'-AGGCTGGCAAGG TACTCCT-3'; GAPDH upstream, 5'-AGGAGCGAGACC CCACTAACAT-3' GAPDH downstream, 5'-GTGATGGCA TGGACTGTGGT-3'. The $20-\mathrm{ml}$ system consisted of $10 \mathrm{ml}$ RT-qPCR-mix, $0.5 \mathrm{ml}$ primer each, $2 \mathrm{ml} \mathrm{cDNA}$ and $7 \mathrm{ml}$ $\mathrm{ddH}_{2} \mathrm{O}$. The PCR condition was set as follows: $95^{\circ} \mathrm{C}$ for $5 \mathrm{~min}$; $95^{\circ} \mathrm{C}$ for $20 \mathrm{sec}, 58^{\circ} \mathrm{C}$ for $30 \mathrm{sec}, 72^{\circ} \mathrm{C}$ for $30 \mathrm{sec}$, for a total of 40 cycles. The expression levels of target genes were calculated with the $2^{-\Delta \Delta \mathrm{Cq}}$ method (23). U6 and GAPDH were used as internal control. 
Enzyme-linked immunosorbent assay (ELISA). Blood sample was centrifuged at $1,000 \mathrm{x} \mathrm{g}$ at $4^{\circ} \mathrm{C}$ for $10 \mathrm{~min}$. ELISA was performed according to the manufacturer's instructions. The standard and sample wells were set on the human NGB ELISA kit (cat. no. FK-QZ1868; Fanke). In total, $50 \mu \mathrm{l}$ standards at indicated concentrations were added into each standard well, while $10 \mu \mathrm{l}$ testing sample was added into the test well (diluted with $40 \mu \mathrm{l}$ diluting solution). Nothing was added to the blank well. Except for the blank wells, $100 \mu$ l horseradish peroxidase (HRP)-labeled detection antibody was added into each standard well and sample well, which were sealed with membrane and incubated for $1 \mathrm{~h}$. After washing, substrates A and B (50 $\mu \mathrm{l}$ each) were added into each well, which were incubated at $37^{\circ} \mathrm{C}$ for $15 \mathrm{~min}$. Then, $50 \mu \mathrm{l}$ stop solution was added into each well. The OD value at $450 \mathrm{~nm}$ was measured with a microplate reader within $15 \mathrm{~min}$.

Western blot analysis. Total protein was extracted with the P0013B RIPA lysis buffer, according to the manufacturer's instructions. The protein concentration was determined with the BCA method (cat. no. RTP7102; Real-times). In total, $20 \mathrm{mg}$ protein sample was separated by $10 \%$ SDS-PAGE, which was then electronically transferred onto a PVDF membrane. After blocking with 5\% non-fat milk at room temperature for $1 \mathrm{~h}$, the membrane was incubated with rabbit anti-human anti-NGB primary antibody (1:1,500 dilution; cat. no. sc-30144; Santa Cruz Biotechnology, Inc.), or rabbit anti-human anti- $\beta$-actin primary antibody (1:3,000 dilution; cat. no. ab129348; Abcam), at $4^{\circ} \mathrm{C}$ overnight. Then, the membrane was incubated with the goat anti-rabbit secondary antibody (1:3,000 dilution; cat. no. ab6721; Abcam) at room temperature at $1 \mathrm{~h}$. Color development was performed with the ECL method (cat. no. ab65623; Abcam). Protein bands were imaged and analyzed with the Image Lab 3.0 software (Bio-Rad Laboratories, Inc.). $\beta$-actin was used as the internal reference.

Bioinformatics prediction. Bioinformatics prediction is currently the basis and main clue for the functional investigation of miRNA. Herein, the miRanda target gene prediction software (http://www.microrna.org/microrna/home.do) was used to search for the target genes that miR-320a might regulate.

Cell culture. The $293 \mathrm{~T}$ cells and CATH.a cells were purchased from The Cell Bank of Type Culture Collection of The Chinese Academy of Sciences. These cells were cultured in RPMI-1640 medium (cat. no. 11875127; Gibco; Thermo Fisher Scientific, Inc.), containing 10\% FBS, in a $5 \% \mathrm{CO}_{2}, 37^{\circ} \mathrm{C}$ incubator. The human serum for cell culture was inactivated at $56^{\circ} \mathrm{C}$ for $30 \mathrm{~min}$, and filtered through $0.22-\mu \mathrm{m}$ micropore, which was used to prepare the RPMI-1640 medium containing 10\% serum. For the cells induced by dexmedetomidine (1 and $10 \mathrm{mM}$, respectively; Jiangsu Hengrui Medicine Co. Ltd), the RPMI-1640 medium containing $10 \%$ FBS was used for cell culture. At $24 \mathrm{~h}$ after induction, the protein indexes were detected. For the co-incubation with NGB recombinant protein (cat. no. ab63278; Abcam), the cells were stimulated with recombinant protein $(1 \mathrm{mg} / \mathrm{l})$ for $48 \mathrm{~h}$.
Cell transfection. Cells in the logarithmic growth phase were inoculated onto 24-well plates, at the density of $3 \times 10^{5}$ cells/well. The cells were cultured with the F12/DMEM medium (Thermo Fisher Scientific, Inc.), containing $10 \%$ FBS, without antibiotics. When $70 \%$ confluence was reached, cell transfection was performed. The transfection plasmid/siRNA/agomiR (100 nM), together with $1 \mathrm{ml}$ Lipofectamine ${ }^{\circledR} 2000$ (Invitrogen; Thermo Fisher Scientific, Inc.), was added to an EP tube containing $50 \mathrm{ml}$ OptiMemi medium (Gibco; Thermo Fisher Scientific, Inc.). After placing at room temperature for $20 \mathrm{~min}$, the mixture was added onto the well to incubate with cells for $6 \mathrm{~h}$. Then, the culture medium was replaced with fresh F12/DMEM medium containing 10\% FBS. After $48 \mathrm{~h}$, the mRNA and protein samples were extracted and detected.

Dual-luciferase reporter assay. The wild-type and mutant seed regions for miR-320a in the 3'-untranslated region (UTR) of the NGB gene were chemically synthesized by Sangon Biotech Co., Ltd., with the Spe-1 and HindIII restriction sites added to both ends. These two DNA fragments were then cloned into the pMIR-REPORT luciferase reporter plasmid (Ambion; Thermo Fisher Scientific, Inc.), and the mutant 3'-UTR seed region was used as the control. In total, $0.8 \mathrm{mg}$ plasmids, containing the wild-type and mutant 3'-UTR DNA sequences, were transfected with Lipofectamine 2000 (Invitrogen; Thermo Fisher Scientific, Inc.) into the $293 \mathrm{~T}$ cells, with the liposome method. Then, the cells were treated with the agomiR-320a (100 nM) for $24 \mathrm{~h}$. The cells were lysed, and the luciferase was detected with the GloMax 20/20 luminometer (Promega Corporation). Renilla was used as internal reference.

MTT assay. After transfection, the cells were seeded onto the 96-well plate, at a density of $2 \times 10^{3}$ cells/well. The experiment was performed in triplicates. At 24, 48 and $72 \mathrm{~h}$, respectively, $20 \mu \mathrm{l}$ MTT $(5 \mathrm{~g} / \mathrm{l})$ was added to incubate with cells at $37^{\circ} \mathrm{C}$ for $4 \mathrm{~h}$. Then, $150 \mu \mathrm{l}$ DMSO was added into each well. The absorption at $490 \mathrm{~nm}$ was determined, and the cell proliferation curve was plotted accordingly.

Statistical analysis. Data are expressed as mean \pm SD. Statistical analysis was performed with the SPSS 18.0 software (SPSS, Inc.). One-way ANOVA was used for comparison of multiple sets of measurement data, with the Dunnett's T3 test; except for data in Figs. 1 and 4, which were analyzed by mixed two-way analysis of variance, and then subjected to Bonferroni analysis. The Student's t-test was used for the comparison between two groups of measurement data. $\mathrm{P}<0.05$ was considered to indicate a statistically significant difference.

\section{Results}

Expression of $N G B$ in serum. Among the recruited subjects, in the dexmedetomidine group, there were 12 males and 8 females, aged 33-60 years old, with the median age of 40.8 years old. In the control group, there were 13 males and 7 females, aged 31-61 years old, with the median age of 41.9 years old (Table SI). To investigate the expression levels of NGB in the serum from the patients before and after surgery, RT-qPCR 
A

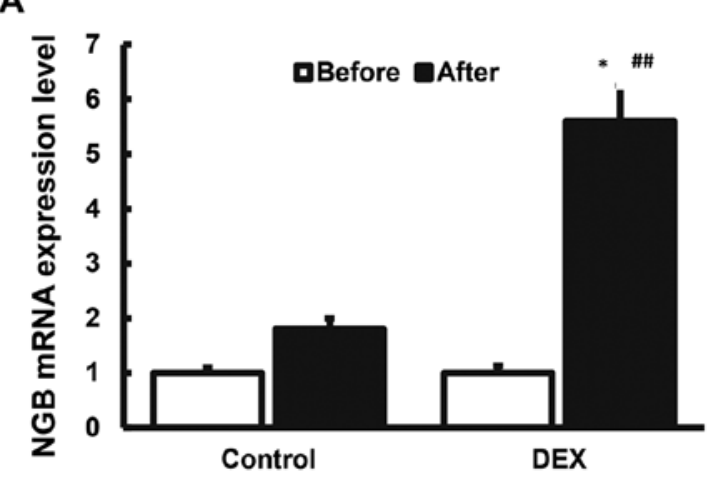

B

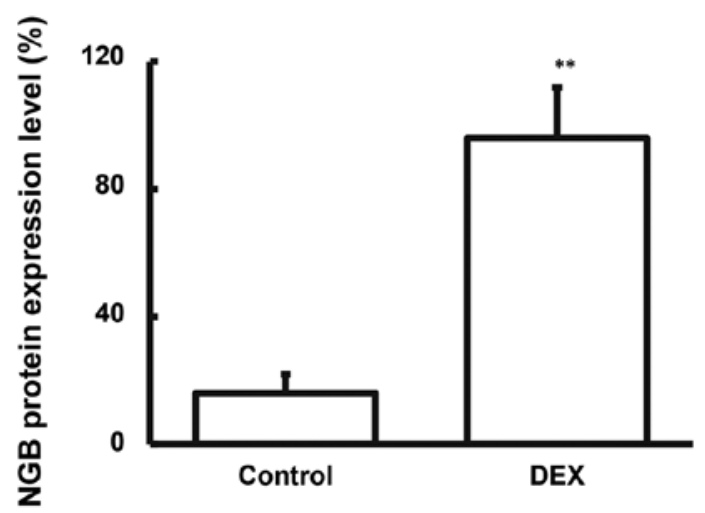

Figure 1. Expression of NGB in serum of patients undergoing OPCABG. (A) The mRNA expression levels of NGB in the serum from patients undergoing OPCABG were detected and compared before and after surgery. (B) Protein expression levels of NGB in the serum of patients undergoing OPCABG were detected. The ratio referred to the amount of NGB in the blood of the patient after the operation/the amount before the operation. ${ }^{*} \mathrm{P}<0.05{ }^{* *} \mathrm{P}<0.01 \mathrm{vs}$. control group; ${ }^{\# \#} \mathrm{P}<0.01$ vs. before surgery. DEX, dexmedetomidine; NGB, neuroglobin; OPCABG, off-pump coronary artery bypass grafting.

A

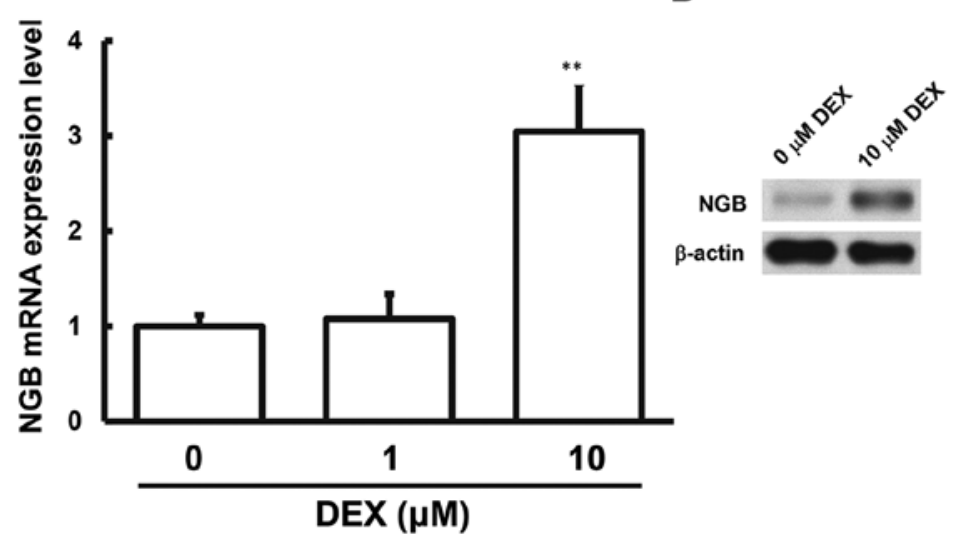

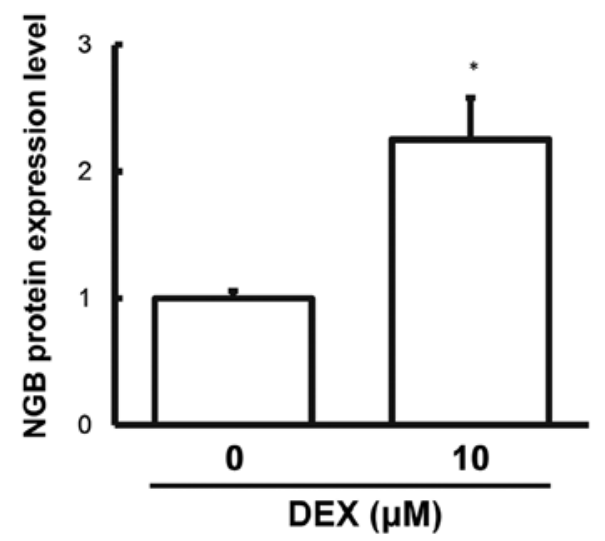

Figure 2. NGB expression levels after dexmedetomidine induction. Human neuronal CATH.a cells were directly induced with dexmedetomidine, and the mRNA (A) and protein (B) expression levels of NGB were then detected. ${ }^{*} \mathrm{P}<0.05,{ }^{* *} \mathrm{P}<0.01$ vs. control (normal saline) group. NGB, neuroglobin; DEX, dexmedetomidine.

and ELISA were performed. The results showed that both the mRNA and protein expression levels of NGB were elevated in the patients after surgery. Moreover, the elevated amplitude of NGB were greater in the dexmedetomidine group (Fig. 1), indicating that the addition of dexmedetomidine during anesthesia may induce the release of NGB in the blood.

NGB expression after dexmedetomidine induction. The human neuronal CATH.a cells were directly induced with dexmedetomidine, and the mRNA and protein expression levels of NGB were then detected. The results showed that, for the induction with $1 \mu \mathrm{M}$ dexmedetomidine, the mRNA expression levels of NGB in the cells was not directly upregulated compared with the control group. However, the induction with $10 \mu \mathrm{M}$ dexmedetomidine significantly elevated the expression levels of NGB in the CATH.a cells. Moreover, the results showed that the protein expression levels of NGB in the cells were significantly upregulated (Fig. 2). Together with the results from the detection of human blood samples in clinic, the aforementioned findings suggest that dexmedetomidine (especially at $10 \mu \mathrm{M}$ ) can induce the NGB expression in the neuronal cells.

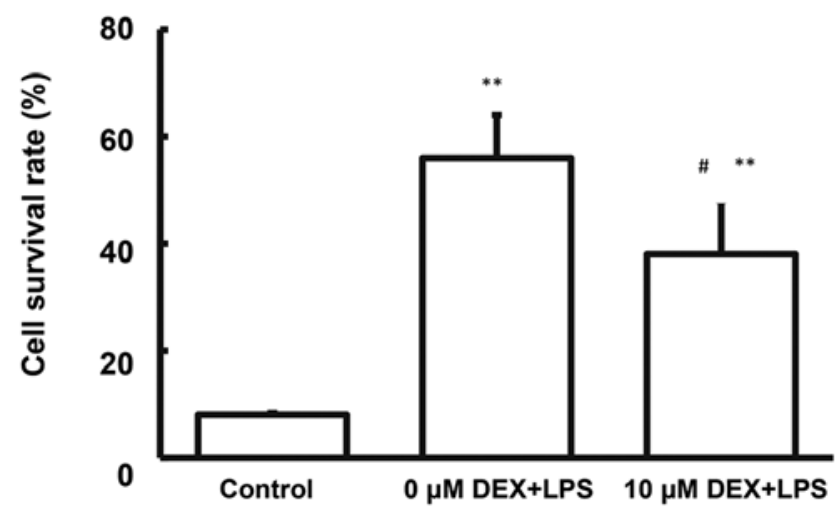

Figure 3. Survival of NGB-pretreated cells upon LPS stimulation. CATH. a cells were directly incubated with NGB recombinant protein, which were then subjected to LPS stimulation. The survival rate was then evaluated. ${ }^{* *} \mathrm{P}<0.01$ vs. control group; ${ }^{\text {}} \mathrm{P}<0.05$ vs. saline +LPS group. NGB, neuroglobin; DEX, dexmedetomidine; LPS, lipopolysaccharide.

Survival of NGB-pre-treated cells with LPS stimulation. The CATH.a cells was directly incubated with NGB recombinant protein, which were then subjected to LPS stimulation to 
A

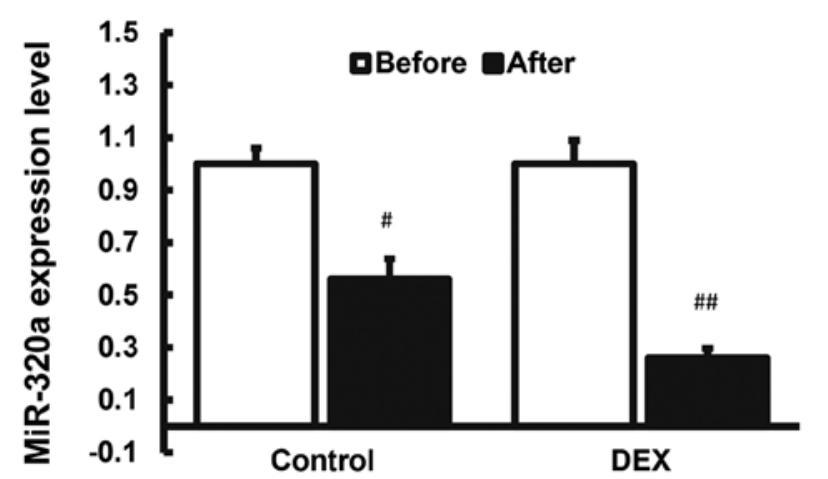

B

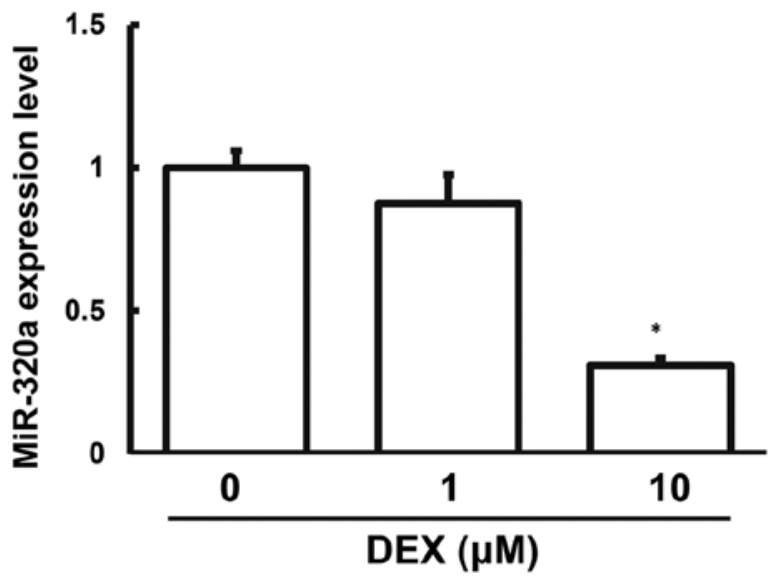

Figure 4. Expression level of miR-320a in serum samples and in cells induced by dexmedetomidine. (A and B) miR-320a levels in the serum samples from patients (A) and in CATH.a cells induced by dexmedetomidine (B) were detected by reverse transcription-quantitative $\mathrm{PCR}$. ${ }^{\#} \mathrm{P}<0.05$, ${ }^{\# \#} \mathrm{P}<0.01$ vs. before surgery; ${ }^{\mathrm{P}}<0.05$ vs. control (normal saline) group. DEX, dexmedetomidine; miR, microRNA.

simulate the survival stress. The results showed that pretreatment with NGB significantly improved the survival of CATH.a cells under LPS stress (Fig. 3). These results suggest that NGB could exert neurologically protective effects, especially for the external stress.

Expression levels of miR-320a in serum samples and in cells induced by dexmedetomidine. The miR-320a has been a predicted potential upstream regulating gene of NGB. Herein, the expression levels of miR-320a in the serum samples from patients and in the CATH.a cells induced by dexmedetomidine were detected with RT-qPCR. The results showed that, in contrast to the elevated NGB expression, the expression level of miR-320a was significantly decreased (Fig. 4). Overall, the results suggest that these two factors (miR-320a and NGB) would have reverse regulatory patterns.

Dual-luciferase reporter assay. Based on the bioinformatics analysis with the miRanda software, the NGB was predicted as a potential target genes for miR-320a (Fig. 5). The results from the dual luciferase reporter assay showed that compared with the control group, the luciferase activity was significantly decreased after co-transfection with the agomiR-320a and pMIR-REPORT luciferase reporter plasmids $(\mathrm{P}<0.05)$, while no significant difference was observed between the control and mutant groups $(\mathrm{P}>0.05)$ (Fig. 6). The results suggest that miR-320a could bind to the 3 '-UTR of NGB to regulate the gene expression.

miR-320a regulates NGB expression and affects neuronal cell proliferation. Next, the agomiR-320a and agomiR-NC were transfected into CATH.a cells, respectively. The results showed that the miR-320a expression levels were significantly elevated in these cells. Moreover, the mRNA and protein expression levels of NGB in the cells were significantly decreased. Meanwhile, the proliferative activity of cells was detected by MTT assay. The proliferative activity of neurons overexpressing miR-320a was significantly decreased (Fig. 7). The aforementioned results suggest that agomiR-320a may affect the neuronal cell proliferation through NGB.

\section{3' agcgggagaguuggGUCGAAAa 5' hsa-miR-320a ||I|||| 477:5' auaaagagaaagagCAGCUUUa 3' NGB}

Figure 5. Bioinformatics prediction analysis. miR, microRNA; NGB, neuroglobin.

\section{Discussion}

POCD is a type of injury of the central nervous system, for which the age has been found as a major risk factor for POCD (24). Moreover, the surgery type has also been shown to represent an important factor in the development of POCD in elderly patients, especially for those undergoing major operation (25). In addition, POCD may also be associated with the surgery type, hypoxia, intraoperative hypotension, stress, alcohol consumption, medication history, cognitive function and other factors (26). Until now, the specific pathogenesis and etiology of POCD have not yet been elucidated. The OPCABG completely avoids the systemic inflammatory responses caused by extracorporeal circulation, which however, needs high level of surgical performance; otherwise it may lead to extremely unstable hemodynamics. Therefore, clinical anesthesia needs to protect the central nervous system and inhibit the inflammatory responses, so as to decrease the incidence of POCD. In the present study, the results showed that pre-administration of dexmedetomidine could decrease the expression levels of miR-320 in the blood samples of patients undergoing OPCABG, which also stimulated the high expression of cerebral hemoglobin and increased the proliferation activity of neuronal cells. The negative association between the miR-320 and NGB was also preliminarily discussed.

Dexmedetomidine is one of the most widely studied anesthesia adjuvants in recent years (27). Dexmedetomidine has mainly been used to regulate the neurotransmitters through acting on locus nucleus in the brain stem of patients. The application of dexmedetomidine in the cardiac surgery would lead to safe and effective outcomes, thus improving 
A

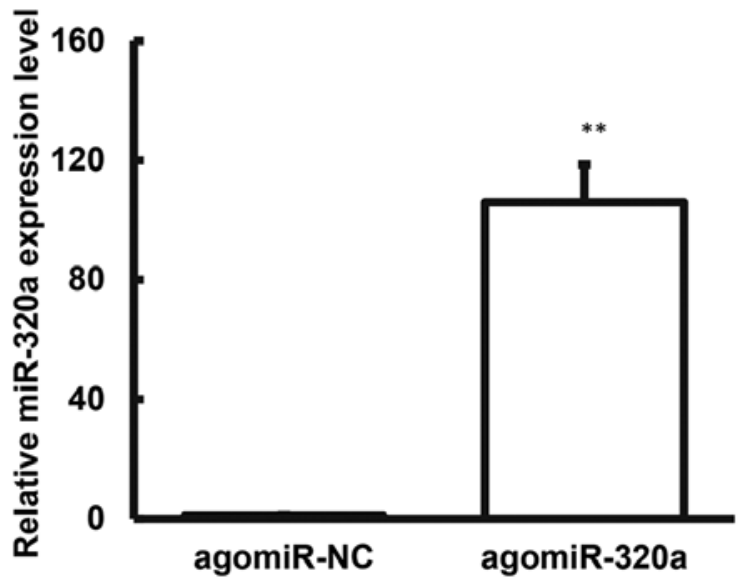

B

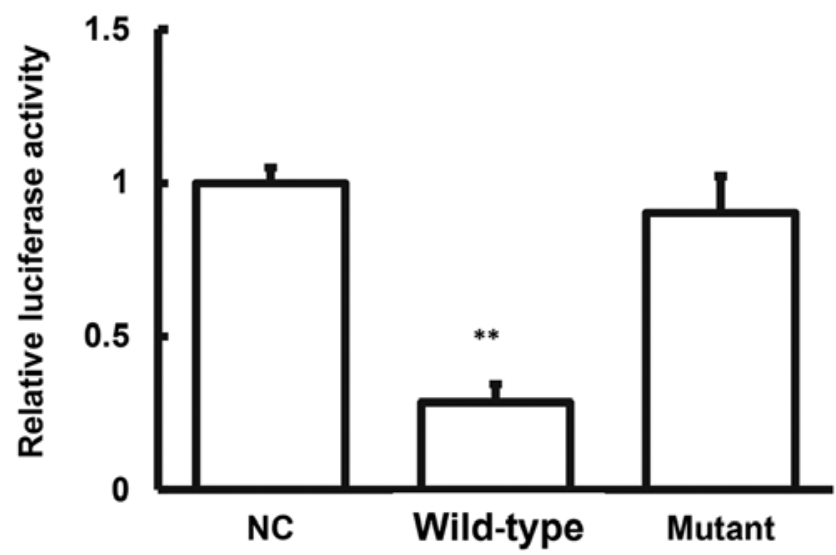

Figure 6. Dual-luciferase reporter assay. (A) Expression level of agomiR-320a in 293T cells transfected with agomiR-320a. (B) Statistical analysis of luciferase activity in these groups. ${ }^{* *} \mathrm{P}<0.01$ vs. agomir-NC group or NC group. miR, microRNA; NC, negative control.

the patient's condition. Dexmedetomidine can selectively excite the $\alpha_{2}$ receptor of the presynaptic membrane, to stimulate the negative feedback effects of sympathetic nerves, thus achieving sedation and inhibiting anxiety and finally decreasing the anesthesia medication (11). It has been shown that dexmedetomidine has a satisfactory effect on decreasing the inflammatory mediators after surgery, and exerts brain-protecting effects in the craniotomy of acute craniocerebral injury (10). Therefore, it was speculated that POCD might have protective and therapeutic effects against inflammatory responses. Moreover, the myocardial protective effects of dexmedetomidine on patients undergoing the OPCABG have been confirmed (28). Currently, it has been shown that dexmedetomidine would alleviate the postoperative cognitive dysfunction in elderly patients. However, the impacts of dexmedetomidine on patients undergoing OPCABG have not yet been reported.

NGB is expressed in the nervous cells of the mammalian nervous systems, as well as in the retina of most mammals (29-32). Overexpressed NGB can lower the neuronal damages under hypoxic conditions and local cerebral ischemia $(33,34)$. The infarct size and oxidative stress have been shown to be significantly decreased in the tissues after stroke in the transgenic mice overexpressing NGB (35). In recent years, NGB has been reported to have a certain role in scavenging ROS. It has been well established that the anti-apoptotic effects of NGB are mainly through the endogenous pathways $(36,37)$. NGB could restore the CytoC, which triggers the apoptotic cascade only in the oxidative state, thereby exerting protective effects. NGB works as a possible endogenous neuroprotective agent in the nervous system. At present, however, there is no relevant study on the effect of dexmedetomidine on the expression of NGB. The present study found that the expression level of NGB in the blood of patients given dexmedetomidine adjunct anesthesia was significantly elevated, suggesting that the elevated NGB expression may be caused by the drug in the brain cells of the patient during OPCABG, which might be one of the underlying protective mechanisms. When the neuronal cells were directly induced by dexmedetomidine, the expression levels of NGB in the cells were also significantly elevated. Pre-incubation of CATH.a cells with NGB antibody significantly increased the survival rate of the cells stimulated with LPS, further confirming the protective effects of NGB on brain cells. However, the specific regulatory mechanism of dexmedetomidine on NGB has not been fully clarified.

The miRNAs usually play biological roles by cleaving mRNAs. The bioinformatics prediction showed that NGB might be a potential target gene for miR-320a. Several studies have reported the role of NGB in the apoptotic pathway. It has been shown that miR-320a is downregulated in various tumor diseases, such as the prostate cancer, glioma, colon cancer and leukemia (38-40). The downregulated expression levels of miR-320a in the liver cancer can promote the invasion of tumor cells and lead to poor prognosis (41). These findings suggest that miR-320a is closely associated with cell proliferation. Therefore, it was speculated that dexmedetomidine might affect the NGB expression levels by regulating miR-320a. The results showed that the expression levels of miR-320a in the blood samples of patients given dexmedetomidine adjunct anesthesia was significantly lower compared with the control group, while the dexmedetomidine induction downregulated the expression levels of miR-320a in the CATH.a cells. The present study results from the dual luciferase reporter assay showed the direct binding between miR-320a and NGB. The cell proliferation activity assay also confirmed that the miR-320a overexpression can lower the proliferation activity of the CATH.a cell line. The aforementioned results suggest that the expression of miR-320a is decreased by dexmedetomidine, which is key to increase the NGB expression levels. However, the limited subjects might be one of the limitations of the present study, and further in-depth studies are still needed with enlarged subject sizes. Moreover, the lack of neuropsychological assessment and analysis of direct interactions between miR-320/NGB and POCD in the cohort might be another limitation of the present study.

In conclusion, the present results showed that pre-administration of dexmedetomidine could increase the expression of NGB in the blood of patients undergoing OPCABG, protecting 
A

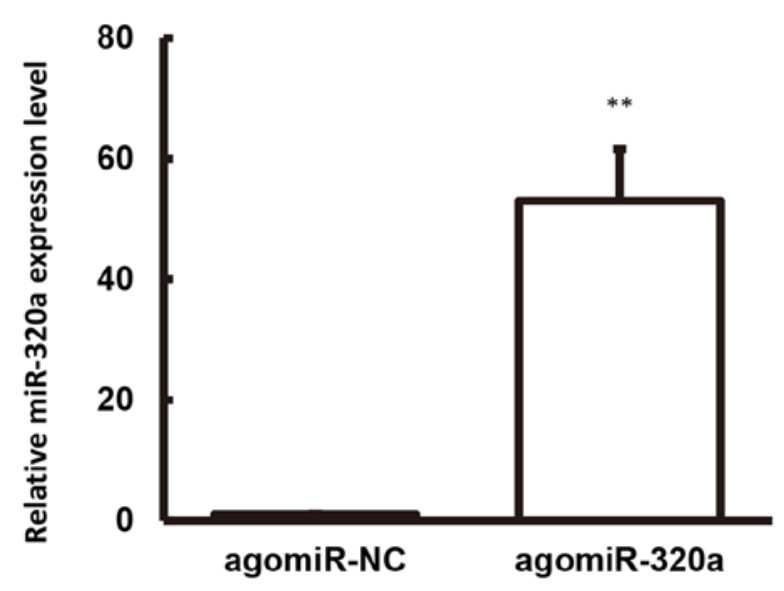

C

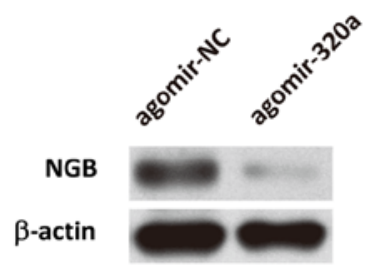

B
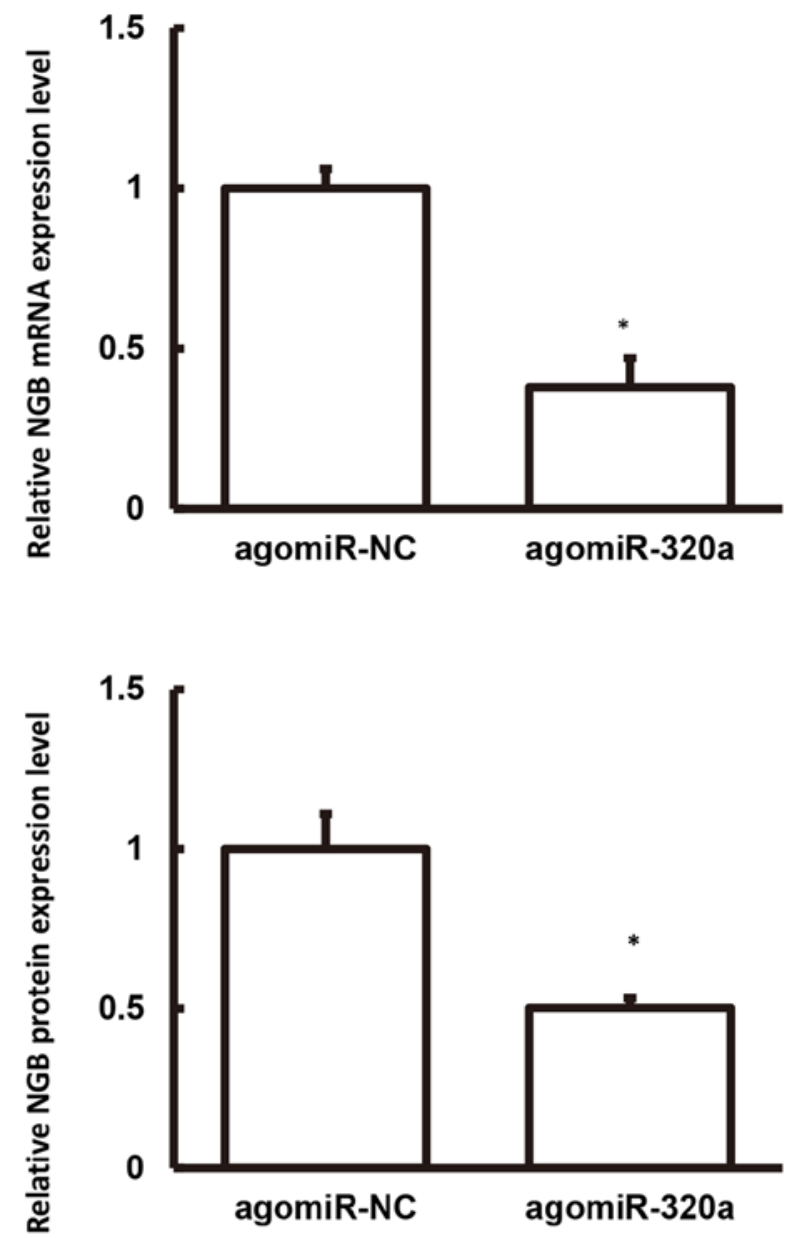

D

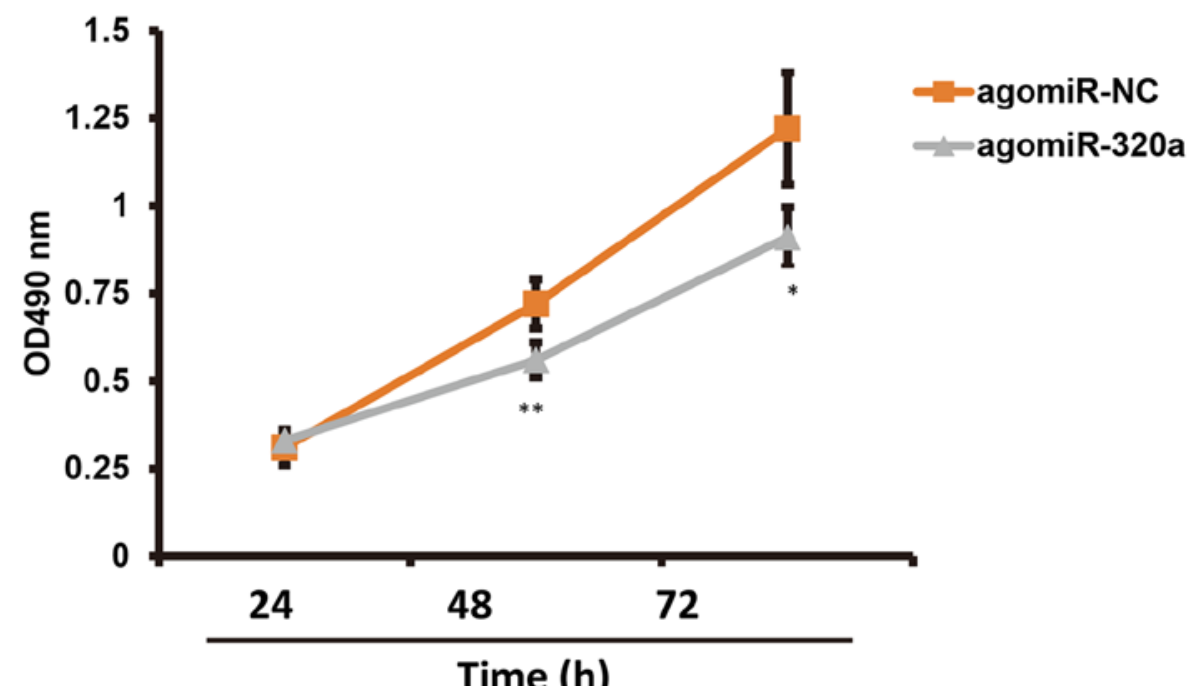

Figure 7. miR-320a regulates NGB expression and affects neuronal cell proliferation. (A) Expression of agomiR-320a in CATH.a cells transfected with agomiR-320a. mRNA (B) and protein (C) expression levels of NGB in cells transfected with agomiR-320a. (D) Cell proliferation activity after agomiR-320a transfection. ${ }^{*} \mathrm{P}<0.05 ;{ }^{* *} \mathrm{P}<0.01$ vs. agomir-NC group. miR, microRNA; NC, negative control; NGB, neuroglobin.

the brain cells. The possible mechanism might be that dexmedetomidine decreases the miR-320a expression and thus, increases the proliferative activity of neuronal cells.

\section{Acknowledgements}

Not applicable. 


\section{Funding}

This work was supported by the Medical Science Research Project of the Health Committee of Hebei Province in 2019 (grant no. 20190890).

\section{Availability of data and materials}

All data generated or analyzed during this study are included in this published article.

\section{Authors' contributions}

YG designed the study, performed the experiments and was a major contributor in writing the manuscript. XZ performed the experiments and drafted the manuscript. HY provided the materials and collected the data. WW and YW analyzed and interpreted the data. FL provided the materials, interpreted the data and revised the manuscript. JT designed the study and provided administrative support. YG and JT confirm the authenticity of all the raw data. All authors read and approved the final manuscript.

\section{Ethics approval and consent to participate}

The study was approved by the ethics review board of the First Affiliated Hospital of Hebei North University. All patients provided written informed consent.

\section{Patient consent for publication}

Not applicable.

\section{Competing interests}

The authors declare that they have no competing interests.

\section{References}

1. Borozdina A, Qeva E, Cinicola M and Bilotta F: Perioperative cognitive evaluation. Curr Opin Anaesthesiol 31: 756-761, 2018.

2. Evered LA and Silbert BS: Postoperative cognitive dysfunction and noncardiac surgery. Anesth Analg 127: 496-505, 2018.

3. Needham MJ, Webb CE and Bryden DC: Postoperative cognitive dysfunction and dementia: What we need to know and do. $\mathrm{Br}$ J Anaesth 119 (Suppl 1): i115-i125, 2017.

4. Niu X, Zhang Q, Xiao D and Zhang Y: A retrospective study of hemodynamic changes in patients after off-pump coronary artery bypass graft surgery using impedance cardiography. Med Sci Monit 25: 3454-3462, 2019.

5. Glumac S, Kardum G, Sodic L, Supe-Domic D and Karanovic N: Effects of dexamethasone on early cognitive decline after cardiac surgery: A randomised controlled trial. Eur J Anaesthesiol 34 776-784, 2017.

6. Glumac S, Kardum G and Karanovic N: Postoperative cognitive decline after cardiac surgery: A narrative review of current knowledge in 2019. Med Sci Monit 25: 3262-3270, 2019.

7. Liu YH, Wang DX, Li LH, Wu XM, Shan GJ, Su Y, Li J, Yu QJ, Shi CX, Huang YN and Sun W: The effects of cardiopulmonary bypass on the number of cerebral microemboli and the incidence of cognitive dysfunction after coronary artery bypass graft surgery. Anesth Analg 109: 1013-1022, 2009.

8. Sanders RD, Xu J, Shu Y, Januszewski A, Halder S, Fidalgo A, Sun P, Hossain M, Ma D and Maze M: Dexmedetomidine attenuates isoflurane-induced neurocognitive impairment in neonatal rats. Anesthesiology 110: 1077-1085, 2009.
9. Han C, Fu R and Lei W: Beneficial effects of dexmedetomidine on early postoperative cognitive dysfunction in pediatric patients with tonsillectomy. Exp Ther Med 16: 420-426, 2018.

10. Ren X, Ma H and Zuo Z: Dexmedetomidine postconditioning reduces brain injury after brain hypoxia-ischemia in neonatal rats. J Neuroimmune Pharmacol 11: 238-247, 2016.

11. Barends CR, Absalom A, van Minnen B, Vissink A and Visser A: Dexmedetomidine versus midazolam in procedural sedation. A systematic review of efficacy and safety. PLoS One 12: e0169525, 2017.

12. Chan AS, Saraswathy S, Rehak M, Ueki M and Rao NA: Neuroglobin protection in retinal ischemia. Invest Ophthalmol Vis Sci 53: 704-711, 2012.

13. Ye SQ, Zhou XY, Lai XJ, Zheng L and Chen XQ: Silencing neuroglobin enhances neuronal vulnerability to oxidative injury by down-regulating 14-3-3gamma. Acta Pharmacol Sin 30: 913-918, 2009.

14. Liu X, Gao Y, Yao H, Zhou L, Sun D and Wang J: Neuroglobin involvement in the course of arsenic toxicity in rat cerebellar granule neurons. Biol Trace Elem Res 155: 439-446, 2013.

15. Khan AA, Mao XO, Banwait S, DerMardirossian CM, Bokoch GM, Jin K and Greenberg DA: Regulation of hypoxic neuronal death signaling by neuroglobin. FASEB 22: 1737-1747, 2008.

16. Uchida Y, Ohshima T, Sasaki Y, Suzuki H, Yanai S, Yamashita N, Nakamura F, Takei K, Ihara Y, Mikoshiba K, et al: Semaphorin3A signalling is mediated via sequential Cdk5 and GSK3beta phosphorylation of CRMP2: Implication of common phosphorylating mechanism underlying axon guidance and Alzheimer's disease. Genes Cells 10: 165-179, 2005.

17. Zhang C, Wang C, Deng M, Li L, Wang H, Fan M, Xu W, Meng F, Qian L and He F: Full-length cDNA cloning of human neuroglobin and tissue expression of rat neuroglobin. Biochem Biophys Res Commun 290: 1411-1419, 2002.

18. Bukauskas T, Kairyte M, Mickus R, Puleikyte L and Macas A: Values of circulating molecular biomarkers (microRNAs) for the evaluation of renal failure during urgent abdominal sepsis anaesthesia. Acta Med Litu 26: 17-24, 2019.

19. Bell JD, Cho JE and Giffard RG: MicroRNA changes in preconditioning-induced neuroprotection. Transl Stroke Res 8: 585-596, 2017.

20. Barik M, Kumar A, Mishra PR and Kapoor PM: Role of MicroRNA in cardiac anesthesia: An innovative consequences and new possibility. Ann Card Anaesth 20: 274-275, 2017.

21. Tadano T, Kakuta Y, Hamada S, Shimodaira Y, Kuroha M, Kawakami Y, Kimura T, Shiga H, Endo K, Masamune A, et al: MicroRNA-320 family is downregulated in colorectal adenoma and affects tumor proliferation by targeting CDK6. World J Gastrointest Oncol 8: 532-542, 2016.

22. White RE and Giffard RG: MicroRNA-320 induces neurite outgrowth by targeting ARPP-19. Neuroreport 23: 590-595, 2012.

23. Livak KJ and Schmittgen TD: Analysis of relative gene expression data using real-time quantitative PCR and the 2(-Delta Delta C(T)) method. Methods 25: 402-408, 2001.

24. Berger M, Nadler JW, Browndyke J, Terrando N, Ponnusamy V, Cohen HJ, Whitson HE and Mathew JP: Postoperative cognitive dysfunction: Minding the gaps in our knowledge of a common postoperative complication in the elderly. Anesthesiol Clin 33: 517-550, 2015.

25. Feinkohl I, Winterer G, Spies CD and Pischon T: Cognitive reserve and the risk of postoperative cognitive dysfunction. Dtsch Arztebl Int 114: 110-117, 2017.

26. Safavynia SA and Goldstein PA: The role of neuroinflammation in postoperative cognitive dysfunction: Moving from hypothesis to treatment. Front Psychiatry 9: 752, 2018.

27. Sottas CE and Anderson BJ: Dexmedetomidine: The new all-in-one drug in paediatric anaesthesia? Curr Opin Anaesthesiol 30: 441-451, 2017.

28. Chi X, Liao M, Chen X, Zhao Y, Yang L, Luo A and Yang H: Dexmedetomidine attenuates myocardial injury in off-pump coronary artery bypass graft surgery. J Cardiothorac Vasc Anesth 30: 44-50, 2016.

29. Wystub S, Laufs T, Schmidt M, Burmester T, Maas U, Saaler-Reinhardt S, Hankeln T and Reuss S: Localization of neuroglobin protein in the mouse brain. Neurosci Lett 346: 114-116, 2003.

30. Reuss S, Saaler-Reinhardt S, Weich B, Wystub S, Reuss MH, Burmester T and Hankeln T: Expression analysis of NGB mRNA in rodent tissues. Neuroscience 115: 645-656, 2002. 
31. Schmidt M, Giessl A, Laufs T, Hankeln T, Wolfrum U and Burmester T: How does the eye breathe? Evidence for neuroglobin-mediated oxygen supply in the mammalian retina. J Biol Chem 278: 1932-1935, 2003.

32. Sun Y, Jin K, Mao XO, Zhu Y and Greenberg DA: NGB is up-regulated by and protects neurons from hypoxic-ischemic injury. Proc Natl Acad Sci USA 98: 15306-15311, 2001.

33. Khan AA, Sun Y, Jin K, Mao XO, Chen S, Ellerby LM and Greenberg DA: A NGB-overexpressing transgenic mouse. Gene 398: 172-176, 2007.

34. Khan AA, Wang Y, Sun Y, Mao XO, Xie L, Miles E, Graboski J, Chen S, Ellerby LM, Jin K and Greenberg DA: Neuroglobin-overexpressing transgenic mice are resistant to cerebral and myocardial ischemia. Proc Natl Acad Sci USA 103: 17944-17948, 2006.

35. Wang X, Liu J, Zhu H, Tejima E, Tsuji K, Murata Y, Atochin DN, Huang PL, Zhang C and Lo EH: Effects of neuroglobin overexpression on acute brain injury and long-term outcomes after focal cerebral ischemia. Stroke 39: 1869-1874, 2008.

36. De Marinis E, Acaz-Fonseca E, Arevalo MA, Ascenzi P Fiocchetti M, Marino M and Garcia-Segura LM: 17 $\beta$-Oestradiol anti-inflammatory effects in primary astrocytes require oestrogen receptor $\beta$-mediated neuroglobin up-regulation. J Neuroendocrinol 25: 260-270, 2013.
37. De Marinis E, Marino M and Ascenzi P: Neuroglobin, estrogens, and neuroprotection. IUBMB Life 63: 140-145, 2011.

38. Sun JY, Huang Y, Li JP, Zhang X, Wang L, Meng YL, Yan B, Bian YQ, Zhao J, Wang WZ, et al: MicroRNA-320a suppresses human colon cancer cell proliferation by directly targeting beta-catenin. Biochem Biophys Res Commun 420: 787-792, 2012.

39. Zhang Y, He X, Liu Y, Ye Y, Zhang H, He P, Zhang Q, Dong L, Liu Y and Dong J: microRNA-320a inhibits tumor invasion by targeting neuropilin 1 and is associated with liver metastasis in colorectal cancer. Oncol Rep 27: 685-694, 2012.

40. Gerber JM, Qin L, Kowalski J, Smith BD, Griffin CA, Vala MS, Collector MI, Perkins B, Zahurak M, Matsui W, et al: Characterization of chronic myeloid leukemia stem cells. Am J Hematol 86: 31-37, 2011.

41. Lu C, Liao Z, Cai M and Zhang G: MicroRNA-320a downregulation mediates human liver cancer cell proliferation through the Wnt//-catenin signaling pathway. Oncol Lett 13: 573-578, 2017.

(i) $($ This work is licensed under a Creative Commons Attribution-NonCommercial-NoDerivatives 4.0 International (CC BY-NC-ND 4.0) License. 